\title{
Steering customers to the online channel: The influence of personal relationships, learning investments, and attitude toward the firm
}

\author{
Dennis Herhausen ${ }^{a, *}$, Marcus Schögel $^{a}$, Matthias Schulten ${ }^{\mathrm{b}}$ \\ ${ }^{a}$ Institute of Marketing, University of St. Gallen, CH-9000 St. Gallen, Switzerland \\ ${ }^{\mathrm{b}}$ Furtwangen University, Digital Media Faculty, 78120 Furtwangen, Germany
}

\section{A R T I C L E I N F O}

Available online 27 March 2012

Keywords:

Customer steering

Channel migration

Multichannel customer management

\begin{abstract}
A B S T R A C T
Understanding the consequences of customer steering is a key challenge of multichannel customer management. Although many firms are faced with the question whether customers should be steered to the online channel to realize the potential benefits of this channel, little is known about the circumstances under which customers will be unreceptive to the online channel and displeased if they are steered. This research addresses this critical gap and examines the impact of customer steering with assortment modifications on customers' online migration decisions and overall satisfaction in three experimental studies. The results highlight the importance of three contingency factors: personal relationships in the current channel, learning investments into the online channel and attitude toward the steering firm.
\end{abstract}

(c) 2012 Elsevier Ltd. All rights reserved.

\section{Introduction}

During the past decade, many firms have implemented online channels in addition to their traditional channels (Geyskens et al., 2002; Neslin et al., 2006). Firms benefit from online channels because online customers are associated with higher levels of loyalty (Shankar et al., 2003), greater retention rates (Hitt and Frei, 2002) and a higher financial performance (Wolk and Skiera, 2009) than traditional channel customers. Furthermore, online channels encourage an increase in the degree of self-servicing by the customer, leading to a more efficient use of a firm's resources and a reduction in customer interaction costs (Falk et al., 2007). As a result of the potential benefits, many firms try to impair migration decisions and steer customers to their online channels (e.g., Ansari et al., 2008; Myers et al., 2004).

One important attribute that determines channel choice is the assortment of a distinct channel (e.g., Inman et al., 2004; Neslin et al., 2006; Verhoef and Donkers, 2005). Not surprisingly, firms use the assortment to steer customers. Apple offers selected products and special discounts only in their online channel and does not offer the whole product assortment in other channels. Many multichannel retailers like Lands' End reduce breadth and frequency of their catalogs and promote additional products or product groups online. However, dysfunctional customer consequences that may result from wrong steering decisions include

\footnotetext{
* Corresponding author. Tel.: +41 71224 2859; fax: +41 712242857.

E-mail address: dennis.herhausen@unisg.ch (D. Herhausen).
}

lower satisfaction, lower loyalty and migration to competitors (Neslin and Shankar, 2009). In addition, customers may react differently to the same migration stimuli (Ansari et al., 2008). Thus, it is important for firms to learn under which circumstances customers will be unreceptive to the online channel and displeased if they are steered.

The purpose of this paper is to fill this critical gap in marketing research by studying how customer steering affects online usage intentions and satisfaction of customers under different contingency factors. More specifically, assortment enlargements are used in the online channel and assortment reductions in the current channel to steer customers. In addition to promoting all products of traditional channels on the Internet, firms enlarge their online assortment by offering exclusive components, benefiting from selling a large number of unique products in relatively small quantities (Anderson, 2008) or clearing traditional channels of unprofitable products to benefit from lower costs (Broniarczyk et al., 1998). Furthermore, by modifying the assortment of a distinct product or product group, firms are able to address a certain customer segment with these migration factors.

However, several contingency factors may affect the success of customer steering (Myers et al., 2004). More specifically, we examine how personal relationships, learning investments and attitude toward the steering firm moderate the effectiveness of steering activities. Personal relationships refer to the strength of personal bonds that develop between customers and employees, thereby strengthening a customer's identity and loyalty with respect to a particular channel and leading to channel lock-in (Beatty et al., 1996). Learning investments include all efforts from 
customers in using a new channel and result in a lack of crosschannel synergy (Verhoef et al., 2007). Attitude toward the steering firm lead to reactions in a consistently favorable or unfavorable way and affect the appraisal and acceptance of steering approaches (Ajzen and Fishbein, 1975).

The study makes several novel contributions relevant for academics and practitioners alike. First, important contingency factors of migration are examined that determine when customer steering is desirable for firms. Second, new insights are gained regarding the impact of encouraged migration on satisfaction. Third, this study follows the recommendations of Ansari et al. (2008) to investigate the effects of customer migration with controlled experiments and therefore allows us to make causal claims of how customer steering affects online usage intentions and satisfaction.

This paper is organized as follows. First, an analytical framework of customer steering with assortment modifications is developed. We then empirically test the impact of assortment modifications on online usage intentions and satisfaction and the three contingency factors. Three studies, including two examining store to online migration and one examining catalog to online migration, help further our understanding of customer steering. The paper closes by summarizing the key findings of the studies, discussing its managerial implications and suggesting directions for future research.

\section{Steering customers with assortment modifications}

Channel value is affected by different characteristics of alternative channels (Neslin et al., 2006). The assortments of specific channels are of particular importance for customer perceptions of channel value (e.g., Baker et al., 2002; Skallerud et al., 2009). If the number of products within an assortment is reduced, perceptions of the assortment are lowered and vice versa. However, in recent years the relationship between assortment reduction and lower perception of assortment received some critique. Contrary to categories with high involvement (e.g. consumer electronics), in categories with low involvement (e.g. groceries) more choice might sometimes be worse (Kuksov and Villas-Boas, 2010). In addition, effects could vary depending on whether the retailer starts with a small or a large assortment (Chernev, 2003). Therefore, we focus in the following on high involvement products and average size assortments to avoid detrimental effects of assortment modifications (Oppewal and Koelemeijer, 2005).

Montoya-Weiss et al. (2003) found that a higher perceived value of one channel over another, for example due to a larger assortment, leads to channel preference. For example, many multichannel firms enlarge their online assortment by offering exclusive components or clear traditional channels of unprofitable products to migrate customers online. The preference for a distinct channel increases the usage of this channel (Venkatesan et al., 2007). Additionally, assortment modifications lead to disconfirmation, which is defined as the comparison of perceived service performance with expectations (Oliver, 1980). Satisfaction emerges when service performance corresponds with expectations (i.e., confirmation) or exceeds them (i.e., positive disconfirmation). In contrast, customer dissatisfaction arises when service performance fails to meet expectations (i.e., negative disconfirmation). A customer's overall satisfaction judgment is influenced by combined experience from multiple channels (Neslin et al., 2006). Due to a lack of experience, customers often have no specific expectations regarding a new channel (Montoya-Weiss et al., 2003). As a result, the current channel constitutes the reference point for customer evaluations.

However, the perceived value of assortment modifications depends on contingency factors. Personal relationships, learning investments and attitude toward the steering firm may all affect the appraisal and acceptance of such steering approaches. Thus, we first focus on the effects of an assortment enlargement and an assortment reduction under favorable contingency factors, namely weak personal relationships, low learning investments and positive attitude toward the steering firm. Subsequently, we introduce the three contingency factors. The resulting conceptual framework of customer steering with assortment modifications is displayed in Fig. 1.

\subsection{The effects of an assortment enlargement}

Following the arguments above, adding relevant items in the online channel increases the service performance of this channel, which in turn enhances the perceived channel value and eventually affects channel preference and channel choice. More specifically, adding items to an average size assortment of high involvement products increases the value of this assortment for customers (Chernev, 2003). Thus, the increase in the perceived value of the online channel through an assortment enlargement is accompanied by a positive disconfirmation of customer expectations regarding the channel (Inman, 2001). Following MontoyaWeiss et al. (2003), positive disconfirmation increases a customer's satisfaction with a channel, which in turn increases overall satisfaction:

H1. Given that contingency factors are favorable, an assortment enlargement in the online channel: (a) increases customer usage intentions for the online channel and; (b) increases overall satisfaction of customers.

\subsection{The effects of an assortment reduction}

An assortment reduction in the current channel may motivate customers to migrate within the multiple channels of a firm through decreased service performance. More specifically, removing items from an average size assortment of high involvement products decreases the value for customers (Chernev, 2003). If this happens in a distinct channel, then the unsatisfying experience may cause customers to reassess the channel value and try another channel (Valentini et al., 2011). Additionally, Montoya-Weiss et al. (2003) found that perceptions of the service quality provided by alternative channels influence online channel use. Falk et al. (2007) provided evidence that offline channel satisfaction reduces the perceived usefulness of the online channel. Following these results, a decline in the service quality of the current channel such as an assortment reduction decreases the perceived value of this channel, which in turn affects channel preference and choice and eventually increases online channel use.

Furthermore, an assortment reduction implies a negative disconfirmation of the current channel. However, this negative effect might be at least partially counterbalanced by a positive disconfirmation of the online channel when performance of this channel matches customers' expectations (Montoya-Weiss et al., 2003). Consequently, Devlin and Yeung (2003) found that customers accept a service level reduction in one channel as long as they are able to benefit from the service level in another channel without difficulties. An example for such a trade-off is provided by Myers et al. (2004) who state evidence that W.W. Grainger, a large US supplier of maintenance parts, was able to keep customers satisfied although the company reduced the service level of the face-to-face channel to steer customers to the Internet channel.

Importantly, this mechanism is affected by the motives and channel preferences of customers (Myers et al., 2004). For example, strong interpersonal relationships may result in a channel lock-in. If customers are faced with a high lock-in, they 
Hypothesized relationships for customer steering with assortment enlargement in the online channel

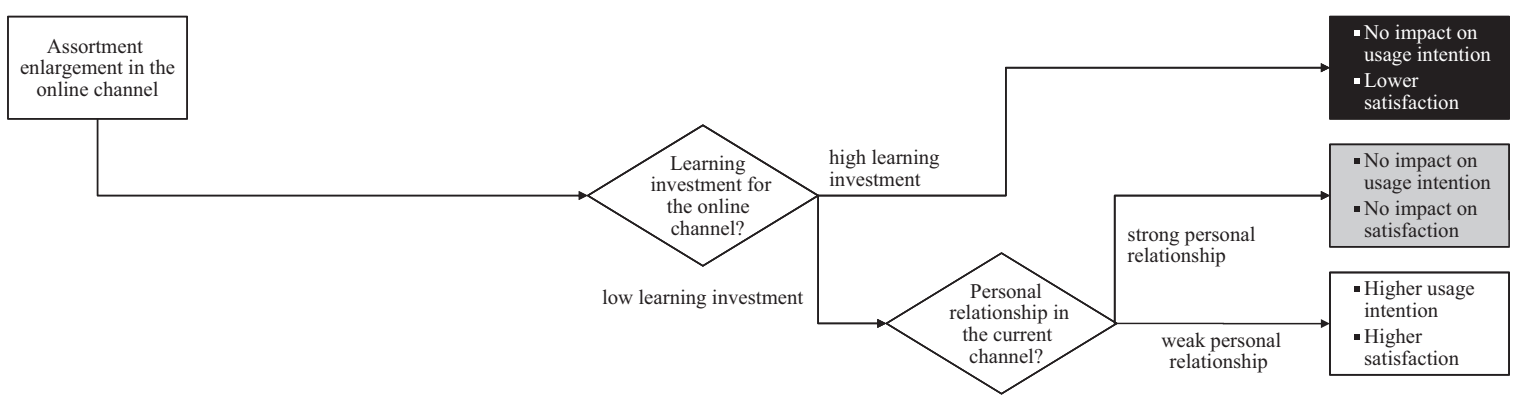

Hypothesized relationships for customer steering with assortment reduction in the current channel

$=$ dysfunctional consequences

$=$ no consequences

$=$ intended consequences

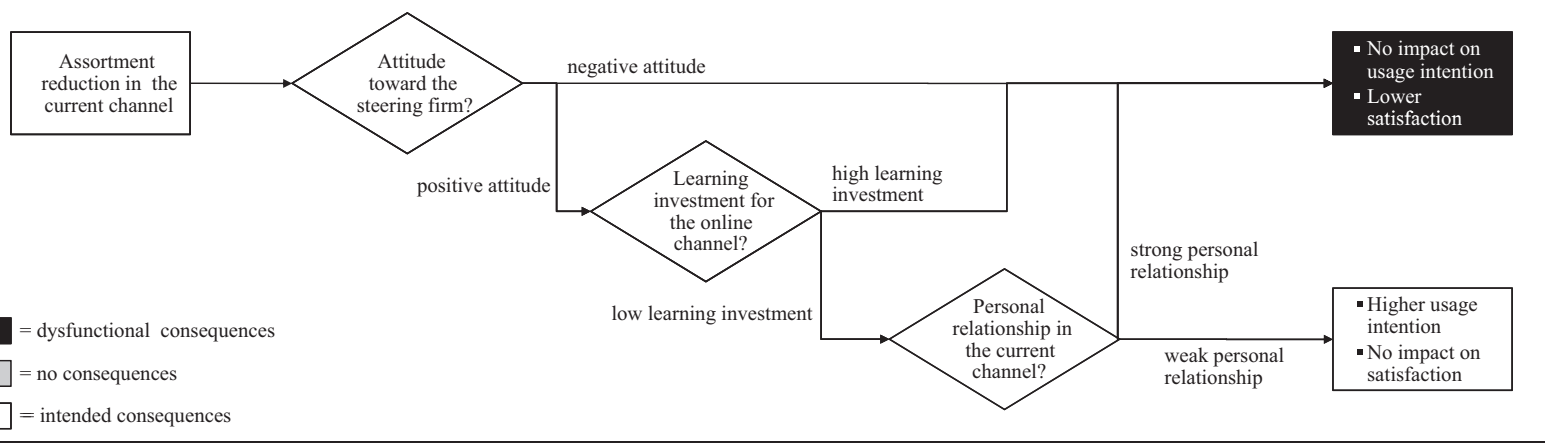

Fig. 1. Conceptual framework.

tend to stick with this particular channel (Verhoef et al., 2007). Thus, a negative disconfirmation of the current channel will not be counterbalanced by the online channel. However, with favorable contingency factors, an assortment reduction may result directly in a negative disconfirmation of the current channel and indirectly in a positive disconfirmation of the online channel, and we assume:

H2. Given that contingency factors are favorable, an assortment reduction in the current channel: (a) increases customer usage intentions for the online channel and; (b) does not decrease overall satisfaction of customers.

\section{The moderating role of personal relationships in the current channel}

Interpersonal relationships are a common reason for channel lock-in. Personal relationships refers to the strength of personal bonds that develop between the customers and employees of a firm (Jones et al., 2000). The contact with a known employee, e.g., at the store channel, strengthens a customer's identification and loyalty with respect to this particular channel (Beatty et al., 1996). Personal relationship loss costs arise when these bonds of identification are disrupted (Burnham et al., 2003). Due to the personal relationship loss costs, having a personal relationship in a specific channel results in channel lock-in and discourages customer migration (Verhoef et al., 2007). Therefore, we assume that a strong personal relationship in the current channel will reduce the positive impact of an assortment modification on online channel usage intention:

H3. The (a) positive effect of assortment enlargement in the online channel and the (b) positive effect of assortment reduction in the current channel on customer usage intentions for the online channel disappear when personal relationships in the current channel are strong.

Faced with relationship loss costs, customers concentrate on the current channel and pay less attention to the characteristics of alternative channels (Burnham et al., 2003). Consequently, they experience a less positive disconfirmation of the online channel and overall satisfaction does not increase. Thus, if customers do not consider migration due to channel lock-in, positive disconfirmation of the online channel resulting from an assortment enlargement does not occur. Furthermore, this also affects assortment reductions. The negative effect is not balanced by a positive disconfirmation of the online channel. Thus, an assortment reduction only leads to a negative disconfirmation of the current channel. Hence, given that personal relationships in the current channel are strong, we assume that assortment enlargement in the online channel does not increase satisfaction, while assortment reduction in the current channel decreases satisfaction:

H4. The (a) positive effect from assortment enlargement in the online channel on overall satisfaction disappears and the (b) neutral effect from assortment reduction in the current channel on overall satisfaction becomes negative when personal relationships in the current channel are strong.

\subsection{Design and participants}

The purpose of Study 1 was to test the interaction between personal relationship and assortment modification. The study has a three (assortment enlargement in the online channel (AE), assortment reduction in the current channel (AR), control group (CG)) $\times$ two (strong personal relationship, weak personal relationship) design. The study was conducted with undergraduate students during a mandatory lecture. All experimental materials for this study and the other studies have been deployed in 
German (see Appendix A for a sample scenario). A total of 197 (53 females, 144 males) students participated in the study. Participation was voluntary and participants were entered into a lottery for free movie tickets as an incentive. On average, the participants were 21.6 years old. A fictitious multichannel firm that sold photo equipment was used in the experiment, and the digital single-lens reflex (SLR) camera assortment was manipulated.

\subsection{Stimuli and procedure}

To examine how assortment modification affects channel usage intention and satisfaction, it was necessary to induce an initial assortment at the beginning of the study. Prior interviews with twelve students showed that digital SLR cameras were of high relevance to participants. More important, digital SLR cameras are high involvement products (Heitmann et al., 2007) and a variety of comparable options from different brands exist. Based on six different photo equipment shops, the average number of digital SLR cameras offered in a low to medium price category was determined to be 7.67 , which we adopted for our original assortment. We used a 50\% enlargement and a 50\% reduction ratio in our scenarios to make participants aware of the assortment advantage in the online channel (Broniarczyk et al., 1998).

Participants first saw a booklet that contained a short description of the fictitious photo equipment specialist that uses a store channel and an online channel. Participants were asked to search for a digital SLR camera for a holiday trip and to imagine the following situation: "You have completed your studies at the University and will soon begin a new, well paid job. In order to reward yourself for all the hard work over the past months, you would like to treat yourself to a vacation in the Maldives. Of course, you would like to take photographic evidence of the blue sea, the white beach and the palm trees. Thus, you decide to search for a new digital SLR camera. In a stack of newspaper, you discover an advertisement of a photo equipment firm, which is about a week old and contains various digital SLR cameras." Subsequently, the advertisement showing the digital SLR camera assortment of eight different cameras, in both the store and online channels, was presented. The illustrative presentation and description of the digital cameras were developed with respect to the various characteristics particularly relevant for a purchase decision as identified by seven owners of digital SLR cameras. A sample assortment is displayed in Fig. 2. After reading through the description at their own pace, participants rated their attitude towards the company, the camera assortment and their likeliness to visit the offline store of the firm.

Turning to the next page, participants read the statement, "In the following, a conversation with an employee of the photo equipment firm regarding the digital SLR cameras in the store is described. Please imagine that you actually experience this situation." In half of the scenarios, the behavior of the employee was professional and reserved (weak personal relationship). In the other half, the behavior of the employee was affectionate (strong personal relationship). Participants saw either an assortment comprised of the same eight cameras (AE, CG) or an assortment reduced to four cameras (AR). We ensured that there was at least one reasonable alternative digital SLR camera for each delisted item within the remaining assortment. The relationship was manipulated through the way in which the employee acted when the participants entered the store, the way he spoke and whether or not they had contact before. For example, under the strong relationship condition, the employee greeted the participant with his or her first name, whereas under the weak relationship condition, the employee greeted the customer politely but in a reserved manner. To avoid confounding effects, the employee was always described as competent and the participant always decided to reconsider his buying decision.

After completing some filler tasks regarding the requirements of the camera on the next page, participants read the statement, "In the following, the online channel of the photo equipment firm is described. Please imagine that you actually experience this situation." The navigation structure of the online channel was described as intuitively utilizable with the same product groups as in the store channel. The same illustrative presentation and description of the cameras as in the store channel was used. Participants saw either an assortment comprised of the same eight cameras (AR, $C G$ ) or an assortment augmented to twelve cameras, including the original cameras (AE). After participants had finished reading the scenario, they rated disconfirmation of offline channel, disconfirmation of online channel, online channel usage intention and subsequent satisfaction. Following this, they responded to several manipulation checks.

\subsection{Measures}

All multi-item measures are displayed in Appendix A. We used disconfirmation of the assortment and relationship loss costs as manipulation checks. To ensure homogeneity across groups, we tested for significant differences in age, gender, frequency and

\begin{tabular}{|c|c|c|c|c|c|c|c|}
\hline $\begin{array}{l}\text { OLYMPUS } \\
\text { E } 420 \text { KIT inkl. } 17\end{array}$ & $\begin{array}{l}\text { CANON } \\
\text { EOS } 450 \text { D KIT + EF }\end{array}$ & $\begin{array}{l}\text { SONY } \\
\text { DSLR-A } 350+18-70\end{array}$ & $\begin{array}{l}\text { SONY } \\
\text { DSLR-A } 230 \text { LSCHWA }\end{array}$ & $\begin{array}{l}\text { PANASONIC } \\
\text { DMC-G } 1 \text { KEG-R ROT }\end{array}$ & $\begin{array}{l}\text { SONY } \\
\text { DSLR-A } 380 \text { L SCHWA }\end{array}$ & $\begin{array}{l}\text { CANON } \\
\text { EOS } 5000+18-55\end{array}$ & $\begin{array}{l}\text { NIKON } \\
\text { D. 90+AFF D D } 18\end{array}$ \\
\hline 10.1 & 12.2 & 12.3 & 10.1 & 12.2 & 15.1 & 12.3 & 15.1 \\
\hline Megapixel & Megapixel & Megapixel & Megapixel & Megapixel & Megapixel & Megapixel & Megapixel \\
\hline 3-time & 3-time & 3-time & 5-time & 3-time & 3-time & 3-time & 5-time \\
\hline $\begin{array}{l}3.5 \text { Pictures / } \\
\text { Sec. }\end{array}$ & $\begin{array}{l}3 \text { Pictures / } \\
\text { Sec. }\end{array}$ & $\begin{array}{l}3.5 \text { Pictures / } \\
\text { Sec. }\end{array}$ & $\begin{array}{l}4 \text { Pictures / } \\
\text { Sec. }\end{array}$ & $\begin{array}{l}3.5 \text { Pictures / } \\
\text { Sec. }\end{array}$ & $\begin{array}{l}3 \text { Pictures / } \\
\text { Sec. }\end{array}$ & $\begin{array}{l}5 \text { Pictures / } \\
\text { Sec. }\end{array}$ & $\begin{array}{l}3.5 \text { Pictures / } \\
\text { Sec. }\end{array}$ \\
\hline 3 inch & $2.5 \mathrm{inch}$ & $2.7 \mathrm{inch}$ & 3 inch & $3 \mathrm{inch}$ & $2.7 \mathrm{inch}$ & $2.7 \mathrm{inch}$ & $2.5 \mathrm{inch}$ \\
\hline Display & Display & Display & Display & Display & Display & Display & Display \\
\hline$€ 540$ & $€ 550$ & $€ 550$ & $€ 520$ & $€ 560$ & $€ 610$ & $€ 580$ & $€ 670$ \\
\hline
\end{tabular}

Fig. 2. Example assortment (original labels in German). 
amount of online purchases, assessment of the camera assortment (all measured by single items) and attitude towards the described retailer.

\subsection{Results}

Participants in the six conditions did not differ by age ( $F(5$, $188)=1.81, p>.11)$, gender $(F(5,189)<1)$, general frequency $(F(5,187)<1)$ or amount $(F(5,186)<1)$ of online purchases. After the initial assortment was introduced, participants evaluated their attitudes towards the company $(F(5,191)<1)$, the camera assortment $(F(5,191)=1.20, p>.31)$ and their likeliness to visit the offline store $(F(5,191)<1)$. No significant differences were found between the groups.

The manipulation checks confirmed that all experimental conditions were introduced successfully in Study 1. As expected, a significant main effect revealed that the personal relationship with the employee was rated as being stronger under the interpersonal sales conversation condition than under the anonymous sales conversation condition $\left(M_{\text {strong_rel }}=5.31, M_{\text {weak_rel }}=3.79, F(1,193)=\right.$ 41.03, $p<.001)$. Enlarging the online assortment $\left(M_{\mathrm{AE}}=4.37\right.$, $\left.M_{\mathrm{CG}}=3.48, F(1,131)=21.90, p<.001\right)$ as well as reducing the store assortment $\left(M_{\mathrm{AR}}=4.03, M_{\mathrm{CG}}=3.48, F(1,127)=8.55, p<.01\right)$ are both associated with positive disconfirmation of expectations regarding the online channel. Participants in the AR condition reported a more negative disconfirmation of expectations regarding the current channel $\left(M_{\mathrm{AR}}=3.71, M_{\mathrm{CG}}=4.16, F(1,127)=7.20, p<.01\right)$. In addition, all participants believed that the description of the scenario is credible $(M=4.76$ on a five-point scale). This judgment did not differ between the conditions $(F(5,193)<1)$.

Online channel usage intention is more strongly affected by assortment modifications under the weak personal relationship condition. Two $2 \times 2$ ANOVAs revealed significant main effects of $\mathrm{AE}(F(1,131)=8.84, p<.005)$ and $\operatorname{AR}(F(1,127)=4.28, p<.05)$ on online channel usage intention. More important, these main effects were qualified by an $\mathrm{AE} \times$ personal relationship interaction $(F(1$, $131)=4.30, p<.05)$ and an $\mathrm{AR} \times$ personal relationship interaction, respectively $(F(1,127)=3.76, p .06)$. Following the logic of hypotheses $\mathrm{H}_{3 \mathrm{a}}$ and $\mathrm{H}_{3 \mathrm{~b}}$, planned contrasts were performed (Fig. 3, Panel A). $\mathrm{AE}\left(M_{\mathrm{AE}}=5.47, M_{\mathrm{CG}}=4.13, F(1,62)=16.41, p<.001\right)$ and $\mathrm{AR}$ $\left(M_{\mathrm{AR}}=5.30, M_{\mathrm{CG}}=4.13, F(1,59)=8.33, p<.005\right)$ had an impact on online channel usage intentions under the weak personal relationship condition. No impact of assortment modifications was found under the strong personal relationship condition $\left(M_{\mathrm{AE}}=4.32\right.$, $\left.\mathrm{M}_{\mathrm{CG}}=4.06, F(1,66)<1 ; M_{\mathrm{AR}}=4.14, M_{\mathrm{CG}}=4.06, F(1,66)<1\right)$.

To examine whether satisfaction had changed after participants were exposed to different scenarios, post-interaction impressions were compared to pre-interaction impressions. These comparisons were achieved by calculating the differences between the two sets of measures. Negative values thus indicate a decrease in satisfaction, whereas positive values indicate an increase. No significant main effect for $\operatorname{AE}(F(1,131)=1.63$, $p>.20$ ) was found. However, the $\mathrm{AE} \times$ personal relationship interaction was significant $(F(1,131)=11.15, p<.001)$. Furthermore, a significant main effect for $\operatorname{AR}(F(1,127)=7.05, p<.01)$ and a significant $\mathrm{AR} \times$ personal relationship interaction $(F(1$, $127)=8.21, p<.005$ ) were found. AE increased satisfaction when participants had a reserved sales conversation with the employee $\left(M_{\mathrm{AE}}=.47, M_{\mathrm{CG}}=-.31, F(1,62)=10.55, p<.002\right)$ and had no significant impact when they had an affectionate sales conversation $\left(M_{\mathrm{AE}}=.15, M_{\mathrm{CG}}=.45, F(1,66)=1.93, p>.16\right)$ (Fig. 3, Panel B). AR did not decrease satisfaction under the weak relationship condition $\left(M_{\mathrm{AR}}=-.26, M_{\mathrm{CG}}=-.31, F(1,59)<1\right)$ but decreased satisfaction under the strong relationship condition $\left(M_{\mathrm{AR}}=-.45\right.$, $\left.M_{\mathrm{CG}}=.45, F(1,66)=16.59, p<.001\right)$.

The results of Study 1 support the notion that customers can be motivated to migrate using assortment enlargement in the online channel $\left(\mathrm{H}_{1 \mathrm{a}}\right)$ as well as assortment reduction in the store channel $\left(\mathrm{H}_{2 \mathrm{a}}\right)$. Additionally, personal relationship in the current channel affected the extent to which both an assortment enlargement in the online channel as well as an assortment reduction in the store channel exhibited their intended effect $\left(\mathrm{H}_{3 a}\right.$ and $\left.\mathrm{H}_{3 \mathrm{~b}}\right)$. Moreover, we found the expected effects on satisfaction. Under the weak relationship condition, enlarging the assortment in the online channel increases satisfaction $\left(\mathrm{H}_{1 \mathrm{~b}}\right)$, while reducing the assortment in the current channel does not affect satisfaction $\left(\mathrm{H}_{2 b}\right)$. Under the strong relationship condition, enlarging the assortment does not affect satisfaction $\left(\mathrm{H}_{3 \mathrm{~b}}\right)$, while reducing the assortment decreases satisfaction $\left(\mathrm{H}_{4 \mathrm{~b}}\right)$.

\section{The moderating role of learning investments into the online channel}

Learning investments decrease cross-channel synergy and refer to the time and effort costs of acquiring new skills or knowledge of how to use a channel effectively (Burnham et al., 2003). These investments are channel-specific and refer to all efforts that must be made to adapt to a new channel. As such, a high learning investment into one channel results in a lack of cross-channel synergy, decreasing the willingness of customers to migrate (Verhoef et al., 2007). The navigation structure is a common reason for perceived ease of use in an online channel and leads to higher learning investment for customers (MontoyaWeiss et al., 2003). Prior research has shown that a complex

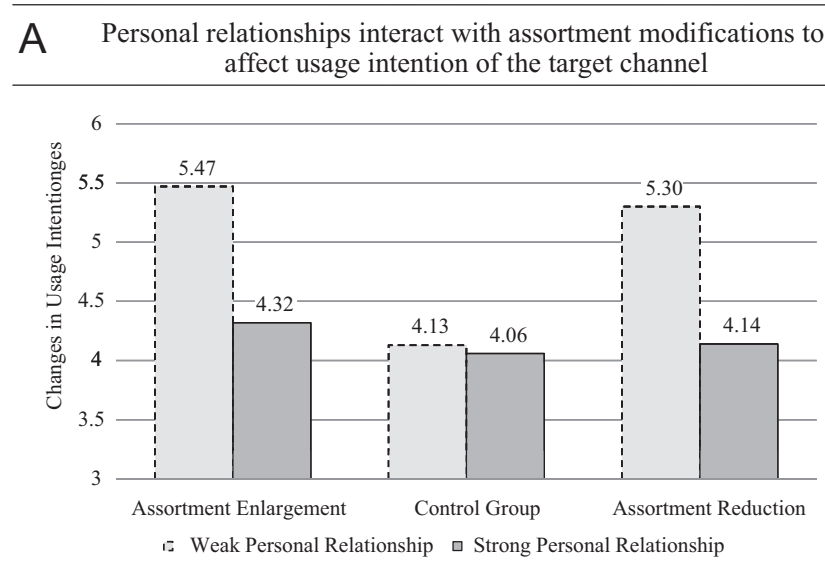

B Personal relationships interact with assortment modifications to affect overall satisfaction

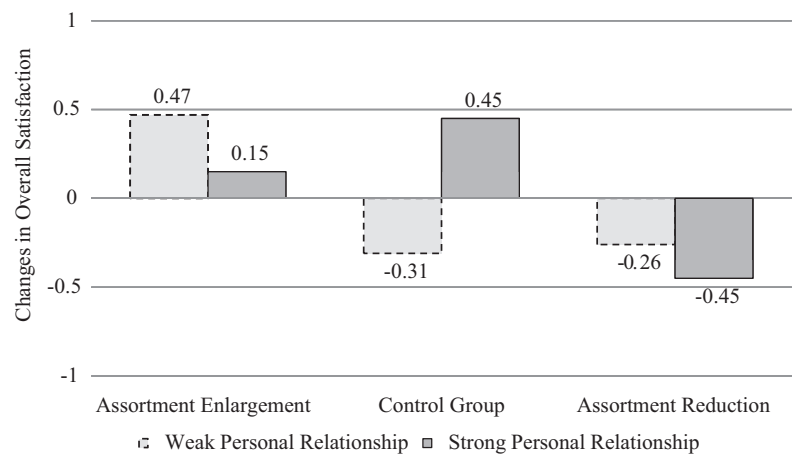

Fig. 3. Interaction between personal relationships and assortment modifications. 
navigation structure affects the amount of shopping effort required to use the online channel of a firm (Hoque and Lohse, 1999). Thus, we assume that a complex navigation structure, which results in high learning investments into the online channel, will reduce the positive impact of assortment modifications on online channel usage intentions:

H5. The (a) positive effect of assortment enlargement in the online channel and the (b) positive effect of assortment reduction in the current channel on customer usage intentions for the online channel disappear when learning investments into the online channel are high.

High learning investments decrease cross-channel synergies and eventually result in a high channel lock-in (Verhoef et al., 2007). Moreover, learning investments directly reduce the attractiveness of alternatives and, consequently, customer perceptions of viable alternative channels (Jones et al., 2000). Thus, if customers are faced with a high learning investment into the online channel, they do not experience a positive disconfirmation of this channel and overall satisfaction will not be increased. In addition, perceived learning costs resulting from learning investments are associated with negative evaluations of new channels (Davis et al., 1989). A negative disconfirmation of the online channel results in a decrease of satisfaction (Montoya-Weiss et al., 2003). Thus, given that learning investments for the online channel are high, we assume that assortment enlargement in the online channel, as well as assortment reduction in the current channel, both decrease satisfaction:

H6. The (a) positive effect of assortment enlargement in the online channel and the (b) neutral effect of assortment reduction in the current channel on overall satisfaction become negative when learning investments into the online channel are high.

\subsection{Design and participants}

The purpose of Study 2 was to test the interaction between learning investments and assortment modification. The study has a three $(\mathrm{AE}, \mathrm{AR}, \mathrm{CG}) \times$ two (low learning investment, high learning investment) design. During a mandatory lecture, a total of 192 (46 females, 146 males) undergraduate students with an average age of 21.8 participated in this study. Participants were different from those of the first study, participation was voluntary and participants were entered into a lottery for free movie tickets as an incentive.

\subsection{Procedure and stimuli}

While the procedure was similar to that described in Study 1, the stimuli in Study 2 were different. We manipulated an assortment of notebook computers from a fictitious retailer and conducted eight interviews with notebook users to ensure that notebooks are high-involvement products and that at least one reasonable alternative for each delisted notebook remained within the assortment. The average number of low-to-mid-priced notebooks offered at four different mass merchandisers in their stores was 5.75; we adopted this assortment for our scenarios. We also used a different enlargement ratio $(+66 \%)$ and reduction ratio $(-66 \%)$ in our scenarios.

Participants saw a booklet that contained a short description of the fictitious mass merchandiser that uses a store channel and an online channel and were asked to search for a new notebook for their studies. It was indicated that the participant has never experienced or heard anything negative about products or prices of the merchandiser. Subsequently, an advertisement showing the assortment of six different notebooks was presented and participants were asked to rate several control variables.
Turning to the next page, participants experienced a scenario in which they went to the store to look for a notebook. The assortment was either still comprised of the same six notebooks (AE, CG) or reduced to two notebooks (AR). Participants were presented an interaction between them and an employee of the mass merchandiser. The behavior of the employee was always described as competent, professional and reserved. Furthermore, it was stated that the participant decided to reconsider his buying decision.

After completing some filler tasks regarding the requirements of the notebook, participants read the statement that they decided to look up the available options in the online channel. In half of the scenarios, the navigation structure was described as intuitively utilizable with the same product groups as in the store channel (low learning investment condition). In the other half, the navigation structure was described as complex, with different product groups than the store channel (high learning investment condition). The assortment in the online channel included the same six notebooks (AR, CG) or was augmented to ten notebooks, including the original notebooks (AE). After participants had finished reading the scenario, they responded to dependent measures and manipulation checks.

\subsection{Measures}

We used the same scales as in Study 1. In addition, participants rated to what extent they would make a learning investment to use the online channel. In Study 1, participants first rated their usage intention for the online channel and then their satisfaction with the retailer. To ensure that the results are not affected by this particular order, the order of evaluation (i.e. usage intention first or customer satisfaction first) was randomized in Study 2.

\subsection{Results}

Age $(F(5,186)<1)$, gender $(F(5,186)=1.55, p>.17)$, frequency of online purchases $(F(5,182)=1.77, p>.12)$ and amount of online purchases $(F(5,182)<1)$ did not differ significantly across the six conditions. No significant differences in attitude toward the company $(F(5,186)=1.60, p>.16)$ and likeliness to visit the store $(F(5,183)=1.32, p>.25)$ were found after introducing the initial assortment. Although assessment of the notebook assortment differed across the conditions $(F(5,186)=2.96, p<.02)$, it did not significantly correlate with usage intention $(r(192)=.01$, $p>.90)$ and overall satisfaction $(r(188)=-.08, p>.29)$. An additional analysis showed no effects for the order of evaluation ( $F(1$, $191)<1$ for both dependent variables).

As expected, learning investment was rated as being higher under the complex navigation structure condition than under the intuitive navigation structure condition $\left(M_{\text {low_li }}=2.04, M_{\text {high_li }}=4.74, F(1\right.$, $190)=21.60, p<.001)$. Enlarging the online assortment $\left(M_{\mathrm{AE}}=4.25\right.$, $\left.M_{\mathrm{CG}}=3.54, F(1,126)=10.34, p<.002\right)$ and reducing the store assortment $\left(M_{\mathrm{AR}}=4.00, M_{\mathrm{CG}}=3.54, F(1,124)=5.11, p<.05\right)$ are both associated with positive disconfirmation of the online channel. Reducing the store assortment is associated with negative disconfirmation of the current channel $\left(M_{\mathrm{AR}}=3.59, \quad M_{\mathrm{CG}}=4.42, \quad F(1\right.$, $126)=26.48 p<.001)$. All described scenarios were perceived as credible $(M=4.25$ on a five-point scale), and judgment did not differ across the six conditions $(F(5,190)<1)$.

Online channel usage intentions were only affected by assortment modifications under the low learning investment condition. No significant main effects for $\operatorname{AE}(F(1,126)=2.63, p>.11)$ and $A R$ $(F(1,122)<1)$ on online channel usage intention were found. However, the $\mathrm{AE} \times$ learning investment interaction $(F(1,127)=$ $9.44, p<.003$ ) as well as the $\mathrm{AR} \times$ learning investment interaction $(F(1,125)=4.44, p<.04)$ were both significant. The learning 


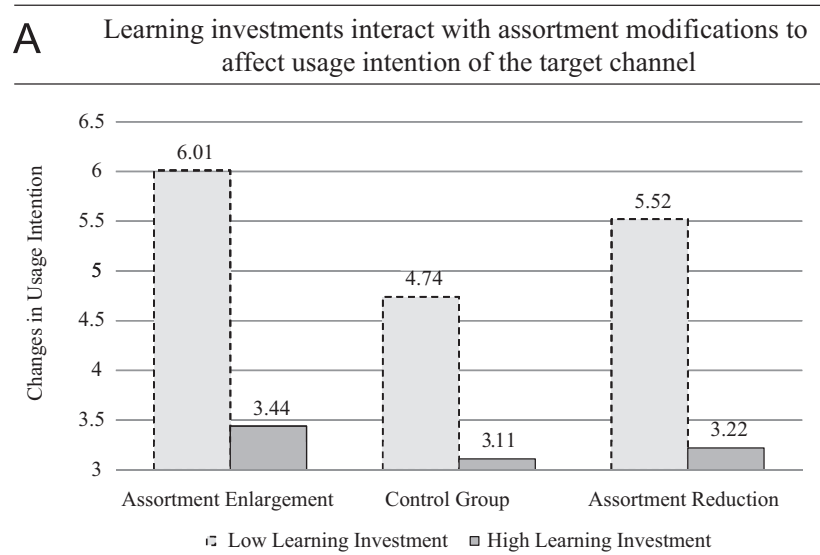
B Learning investments interact with assortment modifications to affect overall satisfaction

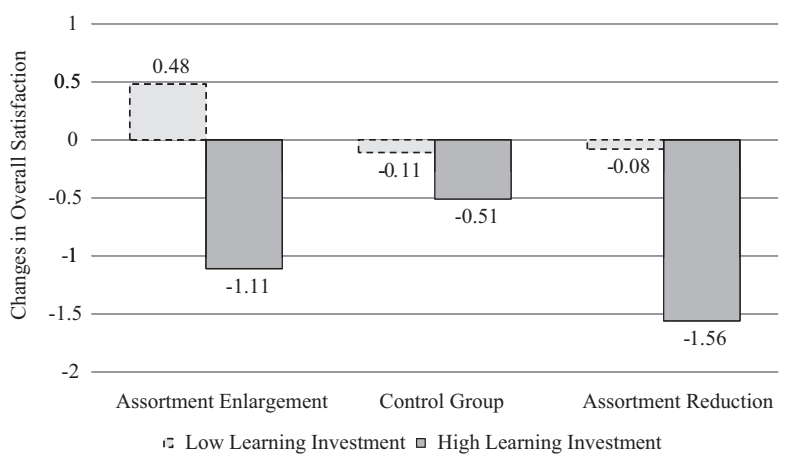

Fig. 4. Interaction between learning investments and assortment modifications.

investment moderated the impact of assortment modifications (Fig. 4, Panel A). AE $\left(M_{\mathrm{AE}}=6.01, M_{\mathrm{CG}}=4.74, F(1,63)=14.37\right.$, $p<.001)$ and $\mathrm{AR}\left(M_{\mathrm{AR}}=5.52, M_{\mathrm{CG}}=4.74, F(1,63)=4.67, p<.05\right)$ had an impact on online channel usage intentions when participants were faced with a low learning investment. No significant effect from migration factors was found when participants were faced with a high learning investment $\left(M_{\mathrm{AE}}=3.44, M_{\mathrm{CG}}=3.11, F(1\right.$, $\left.61)<1 ; M_{\mathrm{AR}}=3.22, M_{\mathrm{CG}}=3.11, F(1,59)<1\right)$.

As hypothesized, the effect of assortment modifications on satisfaction is moderated by the learning investment into the online channel. The analyses revealed no significant main effect for $\operatorname{AE}(F(1,122)<1)$, while a significant $\mathrm{AE} \times$ learning investment interaction was observed $(F(1,131)=11.15, p<.001)$. Furthermore, a significant main effect for AR was found $(F(1,122)=5.52, p<.02)$. More important, the $\mathrm{AR} \times$ learning investment interaction was also significant $(F(1,123)=8.83, p<.004)$. Under the low learning investment condition, $\mathrm{AE}$ increased satisfaction $\left(M_{\mathrm{AE}_{1}}=.48\right.$, $\left.M_{\mathrm{CG}}=-.11, F(1,61)=4.29, p<.05\right)$, while AR did not affect satisfaction $\left(M_{\mathrm{AR}}=-.08, M_{\mathrm{CG}}=-.11, F(1,61)<1\right)$ (Fig. 4, Panel B). Under the high learning investment condition, $\mathrm{AE}\left(M_{\mathrm{AE}}=-1.11\right.$, $\left.M_{\mathrm{CG}}=-.51, F(1,60)=4.60, p<.04\right)$ as well as $\mathrm{AR}\left(M_{\mathrm{AR}}=-1.56\right.$, $\left.M_{\mathrm{CG}}=-.51, F(1,59)=13.82, p<.001\right)$ decreased satisfaction.

Study 2 supported the moderating role of learning investments into the online channel. When customers are faced with a high learning investment, enlarging the assortment in the online channel as well as reducing the assortment in the current channel did not affect usage intention $\left(\mathrm{H}_{5 a}\right.$ and $\left.\mathrm{H}_{5 b}\right)$ and decrease satisfaction $\left(\mathrm{H}_{6 \mathrm{a}}\right.$ and $\left.\mathrm{H}_{6 \mathrm{~b}}\right)$. Yet, Studies 1 and 2 only investigated store to online channel migration. Therefore, we examined catalog channel to online migration in Study 3 to broaden the applicability of our customer migration framework.

\section{The moderating role of attitude toward the steering firm}

Regardless of personal relationships and learning investments, customers may be turned off by being coerced into using channels contrary to their preferences (Neslin and Shankar, 2009). More specifically, due to the role of memory in satisfaction judgments, the attitude toward the steering firm based on unsatisfying experiences can have a profound impact on customer migration (Valentini et al., 2011). Following Mattila (2003), consumers choose to update their summary evaluations stored in memory only when faced with a surprise performance. An assortment enlargement may be perceived as a surprising relationship investment (De Wulf et al., 2001) and motivates customers to update their summary evaluations, in other words counterbalance the negative experience. Notably, customers value the relationship investment even if they do not actually use the online channel (Montoya-Weiss et al., 2003). Thus, the effect of an assortment enlargement is not affected by attitude toward the steering firm. In the following, we focus on the moderating role of attitude toward the steering firm for an assortment reduction.

Myers et al. (2004) use the example of Charles Schwab, an American brokerage and banking company who steered customers from branches to the Internet to point out the importance of customers' positive attitude toward the steering firm when the service level of the current channel is reduced. Additionally, the authors advise against service level reduction in the current channel when attitude is negative because of dysfunctional consequences. Customers with a negative attitude toward the steering firm might perceive a reduction in the service level of the current channel as a confirmation of their negative experience (Mattila, 2003). This strengthens the reliance on the prior judgment and the negative attitude further influence the perceived discrepancy with respect to expectations congruency (Oliver, 1980). Thus, customers will focus on the negative disconfirmation resulting from assortment reduction in the current channel. Moreover, there will be no trade-off through the unchanged assortment in the online channel due to the lack of surprisingly improved performance (Mattila, 2003). Thus, if customers have a negative attitude toward the steering firm, a service reduction may provoke feelings of being forced into another channel and result in reluctance towards the target channel and lower satisfaction (Neslin and Shankar, 2009). We therefore assume that a negative attitude will affect the impact of an assortment reduction on online channel usage intentions and overall satisfaction:

H7. The positive effect of assortment reduction in the current channel on customer usage intentions for the online channel disappears when a customer's attitude toward the steering firm is negative.

H8. The neutral effect of assortment reduction in the current channel on overall satisfaction turns negative when a customer's attitude toward the steering firm is negative.

\subsection{Design and participants}

The purpose of Study 3 was to test the interaction between customer's attitude toward the steering firm and assortment modification. The study has a three $(A E, A R, C G) \times$ two (positive attitude, negative attitude) design. We used the online channel as the target channel and the catalog channel as the current channel and manipulated attitude toward a fictitious mail-order firm with different scenarios. Participants are traditional mail-order 
customers that typically conduct a majority of their orders from the catalog. As such customers are only partly reachable via the Internet, we decided to conduct a postal survey. Overall, 1610 customers with an interest in electronic products were selected from a mail-order firm's database and contacted via postal mail. Participants received gift certificates and were entered into a lottery for a wellness weekend in a high-class hotel as incentives. Within four weeks, 293 usable questionnaires were returned. The age of the participants ranged from 16 to 84 years old, with an average age of 46.5 years; 178 were female and 115 were male.

\subsection{Stimuli and procedure}

The procedure of Study 3 was comparable to those described in the previous studies. A fictitious mail-order company that uses a catalog channel and an online channel was described. Participants were asked to search for a new digital camera for an upcoming holiday, a high involvement product (Heitmann et al., 2007). The attitude toward the steering firm was manipulated through the past experience of the participants. In general, past experience leads to a learned disposition that responds to an object in a consistently favorable or unfavorable way (Ajzen and Fishbein, 1975). This disposition becomes manifest in the attitude, and participants respond to any steering attempts in a consistently favorable or unfavorable way. Within the mail-order business, complete and accurate deliveries determine the quality experience of the physical distribution. Thus, we described either incorrect past deliveries under the negative attitude condition or only correct past deliveries under the positive attitude condition. Based on the main catalogs of five universal mail-order companies, the average number of medium-price digital cameras offered in each catalog was 6.2. We adapted this number and presented the attributes of the digital cameras in an abbreviated format. Participants read the statement, "The catalog includes a total of six digital cameras which are all very different in terms of their brand names, their technical features and their prices. Since you have already looked at other catalogs, you know that this offer is pretty standard for a mail-order company that mainly sells clothing. The mailorder retailer also points out in the catalog that six digital cameras are also offered on his internet site. The cameras are identical to those in the catalog." We then measured attitudes toward the firm, satisfaction and usage intention for the online channel.

After completing some filler tasks on the next pages, the updated assortment of the catalog and the online channel were presented. It was stated either that "the new catalog is half as thick as the old one and only includes three digital cameras. The range of digital cameras has therefore been halved in the new catalog (AR)", or "the new catalog is just as thick as the old one and includes six digital cameras again. The assortment is therefore the same as in the old catalog and as on the old internet page (AE, CG)". In all scenarios, numerous referrals to an updated internet site were described, and the assortment of this internet site was presented. The online assortment included either the same six cameras (AR, CG) or was enlarged to nine cameras (AE), including the original cameras. We ensured that there was at least one reasonable alternative camera for each delisted item within the remaining assortment. On the next page, participants were asked to rate updated online channel usage intentions, updated satisfaction and several manipulation checks.

\subsection{Measures}

Contrary to the students in Studies 1 and 2, participants in Study 3 are traditional mail-order customers and may have little experience with the Internet. Thus, we also checked their ability and experience with the Internet (single item). Additionally, we measured online channel usage intentions before and after participants were exposed to the scenarios. Hence, we were able to analyze the usage intention difference resulting from the assortment modifications.

\subsection{Results}

Participants across the conditions did not differ with respect to age, gender, experience with the Internet or frequency and amount of online purchases (for all: $F(5,287)<1$ ). No significant difference was found between the groups in the assessment of the initial assortment $(F(5,287)=1.09, p>.36)$. An analysis of nonresponse bias revealed no significant differences between early and late respondents on any survey item.

Participants considered their attitudes towards the firm to be less positive under the condition with incorrect and incomplete past deliveries $\left(M_{\text {unfavorable }}=5.60, M_{\text {favorable }}=2.26, F(1,291)=576.22\right.$, $p<.001)$. Enlarging the online assortment $\left(M_{\mathrm{AE}}=4.43, M_{\mathrm{CG}}=3.08\right.$, $F(1,190)=44.41, p<.001$,$) and reducing the catalog assortment$ $\left(M_{\mathrm{AR}}=4.03, M_{\mathrm{CG}}=3.08, F(1,193)=20.73, p<.001\right)$ are both associated with positive disconfirmation of the online channel and reducing the catalog assortment is associated with more negative disconfirmation of the catalog channel $\left(M_{\mathrm{AR}}=2.41, M_{\mathrm{CG}}=3.11, F(1\right.$, $195)=12.64 p<.001$ ). Participants believed that the description of the scenario is credible $(M=4.01$ on a five-point scale); this judgment did not differ across the conditions $(F(5,292)=1.31$, $p>.26)$.

Contrary to Studies 1 and 2, the differences between the two sets of online channel usage intention measures were calculated. While negative values indicate a decrease in usage intentions, positive values indicate an increase. Significant main effects were found for $\operatorname{AE}(F(1,190)=60.49, p<.001)$ and $\operatorname{AR}(F(1,193)=9.86$, $p<.002)$. Moreover, the $\mathrm{AE} \times$ attitude interaction $(F(1,191)<1)$ was insignificant, while the $\mathrm{AR} \times$ attitude interaction $(F(1$, $194)=3.54, p<.07)$ was significant. Attitude moderated the impact of AR (Fig. 5, Panel A). AE $\left(M_{\mathrm{AE}}=1.07, M_{\mathrm{CG}}=-.90, F(1\right.$, $96)=30.19, \quad p<.001)$ and $\mathrm{AR}\left(M_{\mathrm{AR}}=.42, \quad M_{\mathrm{CG}}=-.90, \quad F(1\right.$, $90)=39.01, p<.001)$ both had an impact on online channel usage intentions under the positive attitude condition. No significant impact of AR was found when participants had a negative attitude toward the firm $\left(M_{\mathrm{AR}}=-.78, M_{\mathrm{CG}}=-1.15, F(1,101)<1\right)$; however, AE still had an impact on online channel usage intentions in this condition $\left(M_{\mathrm{AE}}=.76, M_{\mathrm{CG}}=-1.15, F(1,92)=28.77, p<.001\right)$.

The analyses revealed a significant positive main effect for $\mathrm{AE}$ on satisfaction $(F(1,190)=6.45, p<.02)$ but no significant $\mathrm{AE} \times$ attitude interaction $(F(1,191)<1)$. AE increased satisfaction under the positive attitude condition $\left(M_{\mathrm{AE}}=-.19, M_{\mathrm{CG}}=-.72, F(1\right.$, $96)=3.90, p<.07)$ and under the negative attitude condition $\left(M_{\mathrm{AE}}=-.02, M_{\mathrm{CG}}=-.49, F(1,92)=3.15, p<.08\right)$ (Fig. 5, Panel B). AR had a significant negative main effect on satisfaction $(F(1$, $193)=5.88, \quad p<.02$ ). Contrary to our expectations, the $A R \times$ attitude interaction was not significant $(F(1,194)=2.49$, $p>.11)$. However, AR did not significantly affect satisfaction under the positive attitude condition $\left(M_{\mathrm{AR}}=-.87, M_{\mathrm{CG}}=-.72, F(1\right.$, $90)<1$ ), while it decreased satisfaction under the negative attitude condition $\left(M_{\mathrm{AR}}=-1.27, M_{\mathrm{CG}}=-.49, F(1,101)=7.24, p<.009\right)$.

Study 3 demonstrated that customers can also be motivated to migrate from the catalog to the online channel with assortment modifications. Moreover this study supported the moderating role of attitude toward the steering firm. An assortment reduction in the current channel does not increase usage intention $\left(\mathrm{H}_{7}\right)$ and decreases satisfaction $\left(\mathrm{H}_{8}\right)$ when the attitude of the customer is negative. However, even under this condition an assortment enlargement in the online channel still increases usage intention and satisfaction. 


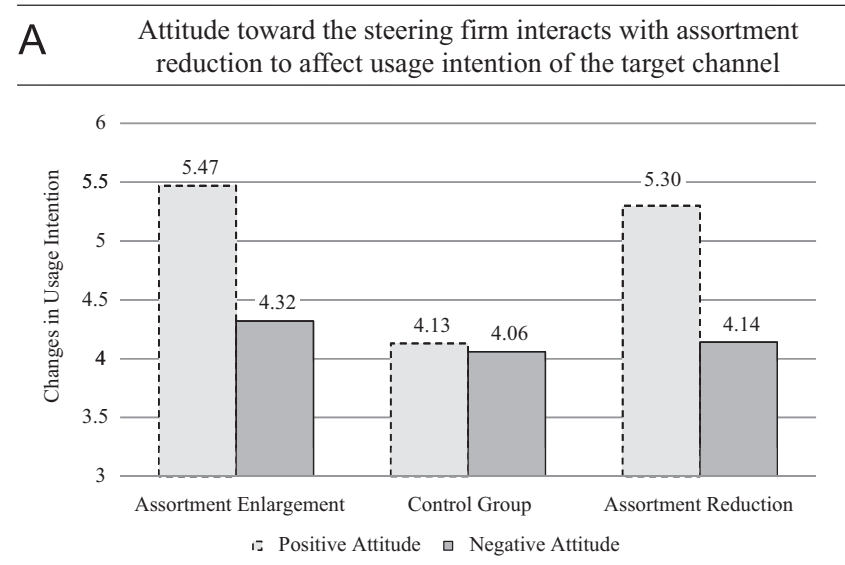

B

Attitude toward the steering firm interacts with assortment reduction to affect overall satisfaction

Fig. 5. Interaction between attitude toward the steering firm and assortment reduction

\section{Discussion}

\subsection{Implications of the results}

In many multichannel firms, marketing professionals are faced with the question whether customers should be steered to the online channel to realize the potential benefits of this channel. We tested the effectiveness of customer steering under three contingency factors: personal relationships, learning investments and attitude toward a firm. Following our results, firms may enlarge the assortment of the online channel or reduce the assortment of the current channel to stimulate channel migration as long as contingency factors are favorable. It is important to note that we controlled for reasonable alternatives for each delisted item in all three studies. To avoid displacing customers to competitors, managers need to ensure this prerequisite for assortment reductions (e.g., Broniarczyk et al., 1998; Sloot et al., 2006). If personal relationships in the current channel are strong or learning investments into the online channel are high, all steering activities are ineffective in increasing the usage intention of the online channel. We found the same ineffectiveness for assortment reductions if customers have a negative attitude toward the steering firm, although they may still be encouraged to migrate as long as they perceive a relationship investment with an assortment enlargement.

When contingency factors are favorable, enlarging the assortment increases overall satisfaction, while an assortment reduction does not necessarily lead to lower satisfaction. However, both assortment modifications decrease satisfaction when learning investments are high, and reducing the assortment in the current channel decreases satisfaction when personal relationship in the current channel is strong or customers have a negative attitude toward the steering company. Under these conditions, we suggest that managers should stay away from steering activities. We surveyed the participants' intentions to switch to a competitor in Study 1 and Study 2 and ran additional analyses to underline the threat of dysfunctional steering consequences. In all groups where satisfaction decreased, competitor switching intention increased, whereas it had no significant differences in other groups. If managers insist on customer steering under the unfavorable contingency conditions, they first should actively reduce relationship loss costs, reduce learning costs, or improve customers' attitude toward their firm.

The contingency factors also provide some indications of appropriate firms and customer segments for steering activities. Low online learning costs call for synergies between channels and weak personal relationships for self-explanatory products and services. Industries that combine these characteristics include, among others, mail-order companies, transport companies and direct banking. Successful examples like flight bookings emphasize the potential of online migration. Customer steering strategies appear less appropriate for industries characterized by strong relationships and high channel learning costs. Business models that require extensive customer services or lack of channel synergies should therefore refrain from customer steering. In addition, contingency factors in channel migration also arise on the customer side (Ansari et al., 2008). Customer segments that appear promising for steering have to combine a low channel lock-in and low online channel switching costs. For example, product experts tend to rely less on personal support from employees and technology-savvy customers tend to have lower online learning costs. These customer segments should be primarily targeted if managers commence steering activities.

\subsection{Limitations and future research}

Although this research contributes to knowledge on customer steering, it also has some limitations that might affect our results and call for future research. In line with all controlled experiments, the current study implies some compromise of external validity. We tried to address this issue and increase the external validity by choosing an event (that is, migrating to the online channel) typical for multichannel customers and modifying migration factors in line with the real assortment of different types of retailers. Moreover, our findings were robust across different assortment manipulation ratios (50\% and 66\%), products (digital cameras and notebooks) and store types (photo equipment shop, mass merchandiser and mail-order company). Another limitation relates to the moderators which we introduced. Motives and channel preferences of customers may result from additional factors than personal relationships, learning investments and attitude toward the steering firm. Thus, characteristics such as buying patterns and attribute-based decisionmaking should be addressed in future customer steering studies. In addition, we focused only on high involvement products and modifications of average size assortments as migration factors in our experiments. Under such conditions, adding items to an assortment provides a benefit for customers (Chernev, 2003). Adding additional items may lead to contrary results in different conditions, like increasing consumer confusion if original assortment is large (Kuksov and Villas-Boas, 2010). Furthermore, common method problems may have occurred. Although we used written scenarios, including images and illustrations, participants read about the different assortments instead of directly 
experiencing them in a multisensory manner (e.g. in an actual store, catalog or website) and our measure for the intention to use the online channel is self-reported.

Beyond these limitations, additional fruitful research directions have emerged from our investigation. First, there are many other ways to migrate customers, e.g. through price discounts, free items or faster services in the online channel as well as extra charges, high fees or reduced services in the current channel. Future research should therefore use our framework to test the impact of other migration measures. Second, customers may use multiple channels in their buying process, e.g. store, catalog and call center simultaneously. The question as to how the presence of other channels affects the success of customer steering provides an interesting area for future studies. Third, although we have incorporated intention to switch to competitors in our experiments, examining how the assortment and the reaction of competitors affect customer steering is an interesting field for further research.

Understanding how channel choice may be influenced without alienating customers will become more and more important for multichannel firms looking to leverage strengths and counterbalance weaknesses of different channels. We suggest that managers should be mindful of the situational differences that result from contingency factors when deriving customer steering strategies.

\section{Acknowledgments}

We thank Daniel Wentzel, Oliver Emrich, Jochen Binder, the anonymous reviewer and the editor of JRCS, Harry Timmermans, for their helpful comments on previous versions of this article.

\section{Appendix A}

A1. Sample scenario for Study 1: assortment enlargement, weak personal relationship (original scenario in German)

Please read the following text very carefully and imagine that you actually experience this situation: You have completed your

Table B1

Construct and items
Online channel usage intention (written for this study)
Will you use the website of the company for future information and purchases? (7-point Likert scale)
1. Likely/unlikely
2. No chance/certain
3. Definitely yes/definitely no

$\alpha$ Study $1 \quad \alpha$ Study $2 \quad \alpha$ Study 3

.96

.94

.97 before
Customer satisfaction (Lam et al., 2004; scale anchors 1 =strongly disagree, $7=$ strongly agree)

1. Overall, I am very satisfied with the assortment and service of the company.

2. Altogether I like the assortment and service very much.

3. All in all the assortment and service accommodate me very well.

4. In sum the assortment and service come up to my expectations.

5. The assortment and service of the company are poor (reversed)
Relationship loss costs (Burnham et al., 2003; scale anchors $1=$ strongly disagree, $7=$ strongly agree)

1. I would miss the help from the people at the store channel if I switched to the online channel.

2. I am comfortable interacting with the people at the store channel.

3. The people at the store channel matter to me.

Learning investment for the online channel (Burnham et al., 2003; scale anchors $1=$ strongly disagree, $7=$ strongly agree)

1. Learning to use the online channel would take time.

2. There is not much involved in understanding the online channel (reversed).

3. I need to consider a certain amount of time to orient myself in the online channel.

\section{.82 before .90 before .92 before \\ .89 after .92 after .96 after}

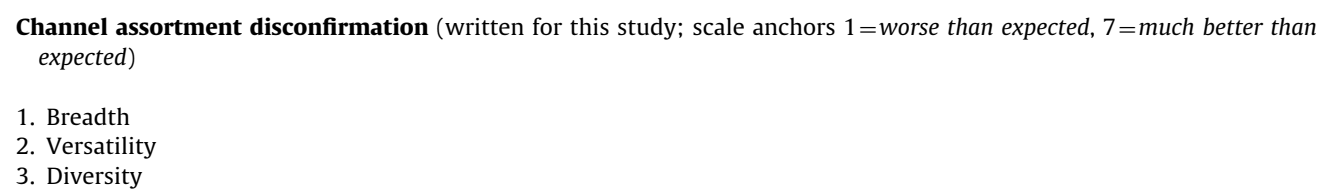

$\begin{array}{lll}.86 & .80 & .97 \\ \text { current } & \text { current } & \text { current } \\ .82 \text { online } & .84 \text { online } & .96 \text { online }\end{array}$

.89

.94

.95

.82 online .84 online .96 online

1. Good/bad

2. Unpleasant/pleasant

3. Harmful/beneficial

4. Favorable/unfavorable

Competitor switching intention (written for this study)

Will you switch to a competitor for future information and purchases? (7-point Likert scale)

.90

1. Likely/unlikely

2. No chance/certain

3. Definitely yes/definitely no 
studies at the University and will soon begin a new, well paid job. In order to reward yourself for all the hard work over the past months, you would like to treat yourself to a vacation in the Maldives. Of course, you would like to take photographic evidence of the blue sea, the white beach and the palm trees. Thus, you decide to search for a new digital SLR camera. In a stack of newspaper, you discover an advertisement of a photo equipment firm, which is about a week old and contains various digital SLR cameras. The 8 different digital SLR cameras from the advertisement are shown in the picture below (see Fig. 2). It is stated in the advertisement that all cameras are available in stores and online alike. So far you have not experienced or heard anything negative about products, prices or services of the photo equipment firm. The store of this firm is located downtown and easily accessible by public transport.

(Controls regarding attitude, assortment and likeliness to visit the store)

In the following, a conversation with an employee of the photo equipment firm regarding the digital SLR cameras in the store is described. Please imagine that you actually experience this situation: Because the cameras from the advertisement appear interesting for you, you decide to visit the store. In the department with the digital SLR cameras you find the following 8 alternatives to choose from, all of them have already been shown in the advertisement. A sales employee, to whom you never had contact before, comes into sight and greets you kindly, "Good day, how can I help you?" After having explained him your interest for a digital SLR camera, he asks how you want to use the camera. He then presents the pros and cons of various camera models related to their features such as maximum resolution, optical zoom, continuous shooting and size of the display. He concludes that, "All 8 cameras are good value for money!" You immerse yourself in the various cameras and consider which one would be best suited for your vacation. After a while the sales person asks you kindly, "Can I still help you with anything?" You negate and he politely thanks you for your interest in the digital SLR cameras and says goodbye. Since you do not want to directly decide on a camera, you consider rethinking your requirements and leaving the store.

\section{(Filler tasks regarding the requirements of the camera)}

In the following, the online channel of the photo equipment firm is described. Please imagine that you actually experience this situation: After reconsidering the requirements of the camera you decide to look up the digital SLR cameras online to compare the available options. The website of the photo equipment store is arranged user-friendly, including a clear menu system and a comprehensible classification of the various product groups. Due to the easy navigation you have no problem to find the page with the digital SLR cameras. You find 12 different models online, including the same 8 digital SLR cameras you have already seen in the advertisement and the store and 4 additional digital SLR cameras. The entire range is shown below. On the website the different digital SLR cameras are compared, so you can weigh the pros and cons of each model easily.

(Questions regarding disconfirmation, usage intention, satisfaction and manipulation checks)

\section{Appendix B}

Construct measures and Cronbach's alpha (original items in German)

See Table B1.

\section{References}

Ajzen, I., Fishbein, M., 1975. Belief, Attitude, Intention and Behavior: An Introduction to Theory and Research. Addison-Wesley Reading, Boston, MA.

Anderson, C., 2008. The Long Tail: Why the Future of Business is Selling Less of More. Hyperion Books, New York, NY.

Ansari, A., Mela, C.F., Neslin, S.A., 2008. Customer channel migration. Journal of Marketing Research 45 (1), 60-76.

Baker, J., Parasuraman, A., Grewal, D., Voss, G.B., 2002. The influence of multiple store environment cues on perceived merchandise value and patronage intentions. Journal of Marketing 66 (2), 120-141.

Beatty, S.E., Mayer, M., Coleman, J.E., Reynolds, K.E., Lee, J., 1996. Customer-sales associate retail relationships. Journal of Retailing 72 (3), 223-247.

Broniarczyk, S.M., Hoyer, W.D., McAlister, L., 1998. Consumers' perceptions of the assortment offered in a grocery category: the impact of item reduction. Journal of Marketing Research 35 (2), 166-176.

Burnham, T.A., Frels, J.K., Mahajan, V., 2003. Consumer switching costs: a typology antecedents, and consequences. Journal of the Academy of Marketing Science 31 (2), 109-126.

Chernev, A., 2003. When more is less and less is more: the role of ideal point availability and assortment in consumer choice. The Journal of Consumer Research 30 (2), 170-183.

Davis, F.D., Bagozzi, R.P., Warshaw, P.R., 1989. User acceptance of computer technology: a comparison of two theoretical models. Management Science 35 (8), 982-1003.

Devlin, J.F., Yeung, M., 2003. Insights into customer motivations for switching to Internet banking. International Review of Retail, Distribution and Consumer Research 13 (4), 375-392.

De Wulf, K., Odekerken-Schröder, G., Iacobucci, D., 2001. Investments in consumer relationships: a cross-country and cross-industry exploration. Journal of Marketing 65 (4), 33-50.

Falk, T., Schepers, J., Hammerschmidt, M., Bauer, H.H., 2007. Identifying crosschannel dissynergies for multichannel service providers. Journal of Service Research 10 (2), 143-160.

Geyskens, I., Gielens, K., Dekimpe, M.G., 2002. The market valuation of internet channel additions. Journal of Marketing 66 (2), 102-119.

Heitmann, M., Lehmann, D.R., Herrmann, A., 2007. Choice goal attainment and decision and consumption satisfaction. Journal of Marketing Research 44 (2), 234-250.

Hitt, L.M., Frei, F.X., 2002. Do better customers utilize electronic distribution channels? The case of PC banking. Management Science 48 (6), 732-748.

Hoque, A.Y., Lohse, G.L., 1999. An information search cost perspective for designing interfaces for electronic commerce. Journal of Marketing Research 36 (3), 387-394.

Inman, J.J., 2001. The role of sensory-specific satiety in attribute-level variety seeking. Journal of Consumer Research 28 (1), 105-120.

Inman, J.J., Shankar, V., Ferraro, R., 2004. The roles of channel-category associations and geodemographics in channel patronage. Journal of Marketing 68 (2) $51-71$.

Jones, M.A., Mothersbaugh, D.L., Beatty, S.E., 2000. Switching barriers and repurchase intentions in services. Journal of Retailing 76 (2), 259-274.

Kuksov, D., Villas-Boas, J.M., 2010. When more alternatives lead to less choice Marketing Science 29 (3), 507-524.

Lam, S.Y., Shankar, V., Erramilli, M.K., Murthy, B., 2004. Customer value, satisfaction, loyalty, and switching costs: an illustration from a business-to-business service context. Journal of the Academy of Marketing Science 32 (3), 293-311.

Mattila, A.S., 2003. The impact of cognitive inertia on postconsumption evaluation processes. Journal of the Academy of Marketing Science 31 (3), 287-299.

Montoya-Weiss, M.M., Voss, G.B., Grewal, D., 2003. Determinants of online channel use and overall satisfaction with a relational, multichannel service provider. Journal of the Academy of Marketing Science 31 (4), 448-458.

Myers, J.B., Pickersgill, A.D., Van Metre, E.S., 2004. Steering customers to the right channels. McKinsey Quarterly 2004 (4), 36-47.

Neslin, S.A., Grewal, D., Leghorn, R., Shankar, V., Teerling, M.L., Thomas, J.S. Verhoef, P.C., 2006. Challenges and opportunities in multichannel customer management. Journal of Service Research 9 (2), 95-112.

Neslin, S.A., Shankar, V., 2009. Key issues in multichannel customer management: current knowledge and future directions. Journal of Interactive Marketing 23 (1), 70-81.

Oliver, R.L., 1980. A cognitive model of the antecedents and consequences of satisfaction decisions. Journal of Marketing Research 17 (4), 460-469.

Oppewal, H., Koelemeijer, K., 2005. More choice is better: effects of assortment size and composition on assortment evaluation. International Journal of Research in Marketing 22 (1), 45-60.

Shankar, V., Smith, A.K., Rangaswamy, A., 2003. Customer satisfaction and loyalty in online and offline environments. International Journal of Research in Marketing 20 (2), 153-175.

Skallerud, K., Korneliussen, T., Olsen, S.O., 2009. An examination of consumers' cross-shopping behaviour. Journal of Retailing and Consumer Services 16 (3) $181-189$.

Sloot, L.M., Fok, D., Verhoef, P.C., 2006. The short-and long-term impact of an assortment reduction on category sales. Journal of Marketing Research 43 (4), 536-548.

Valentini, S., Montaguti, E., Neslin, S., 2011. Decision process evolution in custome channel choice. Journal of Marketing 75 (6), 72-86. 
Venkatesan, R., Kumar, V., Ravishanker, N., 2007. Multichannel shopping: causes and consequences. Journal of Marketing 71 (2), 114-132.

Verhoef, P.C., Donkers, B., 2005. The effect of acquisition channels on customer loyalty and cross-buying. Journal of Interactive Marketing 19 (2), 31-43.
Verhoef, P.C., Neslin, S.A., Vroomen, B., 2007. Multichannel customer management: understanding the research-shopper phenomenon. International Journal of Research in Marketing 24 (2), 129-148.

Wolk, A., Skiera, B., 2009. Antecedents and consequences of Internet channel performance. Journal of Retailing and Consumer Services 16 (3), 163-173. 